\title{
A Pin-On-Disk Study of Rail and Wheel in Dry and Mist Environments
}

\author{
Sachin, Rabesh Kumar Singh*, and Anuj Kumar Sharma \\ Centre for Advanced Studies, Dr. A.P.J. Abdul Kalam Technical University, Lucknow, India, 226031
}

\begin{abstract}
The railways operate in various varying environmental conditions. The working environments affects the tribology of the rail and wheel contact. Therefore, the tribological properties of rail and wheel contact become important to study in these conditions. Commonly, rail and wheel contact functions under mist and wet conditions. The present study is conducted to analyse the behaviour of friction force and wear under dry, water with MQL and wet condition. The MQL is used to generate the mist condition. The study is performed on pin-on-disk tribometer in which pin is made of rail track material and disk is made of wheel material. From the experiments it was found that the friction force and wear both decreases significantly for mist condition as compared to dry condition and is least for wet condition. It was also noted that if load is increased the friction force and wear depth are also increases under all three conditions.
\end{abstract}

\section{Introduction}

The railway system of any country is an important player in economy of the country by transporting goods and people and by employing large number of people. The Indian railways has one of the biggest rail network in India and is fourth largest rail network in the world. One of the major challenges in smooth functioning of railways is wear of rail track and rail wheel. There are various factors which are responsible for wear and fracture in rail and wheels. In most of the environmental conditions the functioning of railways is affected. The rail wheel contact has both rolling as well as sliding. In between wheel's flange and rail head, sliding is dominant. On the other hand, the rolling is at wheel tread and rail head contact [1]. The rail wheel contact zone is roughly $1 \mathrm{~cm}^{2}$. The wheel flange and the rail head contact has higher coefficient of friction, slip and load conditions are also high and this means wear and rolling contact fatigue are high here [2]. The environment in which railway functions, affects the wear and friction significantly. In a study, Zhu et al. [3] investigated the effect of temperature and humidity and found that increase in relative humidity causes the friction to reduce up to a saturation level. In another study, it was found that above $70 \%$ relative humidity, friction was low and at $40 \%$ relative humidity the friction level was at par with dry level. In the same study, it was also found that contaminants like $\mathrm{Fe}_{2} \mathrm{O}_{3}$ and $\mathrm{Fe}_{3} \mathrm{O}_{4}$ both increase frictional force while after some time it is increasing at a greater rate because of the greater particle size. $\mathrm{Fe}_{2} \mathrm{O}_{3}$ and $\mathrm{Fe}_{3} \mathrm{O}_{4}$ both are railhead contaminant [4]. The effect of humidity was also studied by Olofsson et al. [5] and found that the relative humidity if increased, brings down the coefficient of friction. They also found that when elm leaves are used as a lubricant, the coefficient of friction reduces further and also, the leaves if present along with lubricants used in railway systems, tends to compromise the functioning of lubricant. Another experiment has been conducted on the twin disk, it was found that there is highest traction coefficient for dry condition and lowest for oils [6]. The study done by Zhu et al. [7] confirmed that with increase in humidity, the friction coefficient decreases rapidly and at elevated humidity the coefficient of friction is less sensitive to relative humidity.

The temperature also affects the rail wheel contact conditions. A study by Yadav et al. [8] gave insight into the role of temperature on rail wheel contact, and it was found that due to increase in temperature, the friction levels decreases. Another study about the effect of temperature on sliding wear of metal support the fact that, with increase in temperature friction force and wear are reduced because the oxidation of wear debris formation takes place and also the elevated temperature assist in compaction of debris which in turn forms a wear protective layer [9].

Other environment conditions like presence of sand, cement and the sulphur affects the coefficient of friction. Khalladi et al. [1] found that sand provides higher adhesion which means as compared to dry conditions, and has more friction levels and the silica grains which are found in the sand penetrates in the rail wheel contact and causes surface damage to both rail as well as wheel material. The sand particle acts as abrasives and causes abrasive wear.

The snow particle in rail wheel also has effect on the wear and friction levels. A study showed that the

${ }^{*}$ Corresponding author: rasm.singh@gmail.com 
coefficient of friction lowers dramatically if snow is present. Because of pressure melting, the snow particle melt into liquid like layer and haematite formation takes place at contacts and it reduces wear and friction levels [10]. The adhesion between rail and wheel decreases significantly when the water is introduced between the rail and wheel contact [11]. The temperature of water present in between rail wheel contact affects adhesion. With the increase in temperature, the adhesion coefficient increases [12]. Similar type of effect is also shown by surface roughness which means increase in surface roughness causes increase in adhesive coefficient. [13]

If there is grease in between the rail wheel contact, the coefficient of friction is very low and is lower as compared to the condition when water is there in between the rail and wheel [14]. Leaves affect the coefficient of friction and wear significantly in rail wheel contact condition as discussed earlier. The leaves reduce wear and coefficient of friction. Leaves form a slippery coating and they also form chemically reacting surface when crushed in rail wheel contact [15].

In another study, effect of acting pressure was studied by Deters et al. [16] and Ravikiran et al. [17] and they noticed that increase in wear volume was proportional to increase in acting pressure.

There are multiple mechanisms responsible for wear in rail wheel contact. If the relative humidity is less than $70 \%$ adhesive wear dominates. At higher relative humidity, wear due to corrosion dominates [18]. When there are some third body particles like sand, abrasive wear occurs as already discussed. The sand is used for adhesion between rail and wheel when adhesion becomes lower than desired level. The delamination wear is there because the rail is comparatively softer than wheel and the wheel is hard therefore delamination can be take place. Surface fatigue wear happens because the contact has alternating stress and crack happens because of fatigue [19]. The high stress at the rail and wheel cause some surface damage because of rolling contact fatigue (RCF) and it is unavoidable in normal operation of railways. The surface damage can be lowered if high strength steels are used. Lubrication can also reduce surface damage and if bogies steer well it can reduce the surface damage [20].

This paper deals with the study of wear as well as friction behaviour at the rail and wheel interface under different environmental conditions using the pin-on-disk tribometer. First condition is dry condition, (no contaminant) the other condition is being the use of water in mist form with MQL. The MQL can generate the mist of water in fine droplets. In third condition water is used in the flooded mode. These three environmental conditions are common for the railways operations. Therefore, these three conditions are compared in this study keeping load constant at ambient room temperature and at ambient relative humidity.

\section{Materials and experiment}

\subsection{Experimental setup}

Fig. 1 shows the pin-on-disk tribometer which is used for the experimentation. The setup consists of a rotating disk with a holder for pin, along with a controller for setting up run time and rotational speed (rpm). The controller also has display units inbuilt in it. One display tells the value of wear in $\mathrm{mm}$. Other display tells friction force in $\mathrm{N}$. There is also a monitor to observe real time graph of friction force and wear.



Fig. 1. Tribometer setup which includes, rotating disk, pin holder, controller and monitor.

For this particular experiment the disk is made up of wheel material which is fixed in a holder and both are attached to the machine. The pin which is made up of rail track material is fixed in the pin holder during the experiment. The setup is placed in a proper ventilated setup having a temperature of $24.9^{\circ} \mathrm{C}$ and $66 \%$ of relative humidity. The setup uses proximity sensor for speed of the rotating disk. For frictional force it uses load cells and it uses LVDT to measure wear. The accuracy of this pinon-disk setup is $0.1 \pm 1 \%$.

The setup also included a facility to use water as MQL and suitable arrangement was made for the purpose as shown in Fig. 2 and Fig. 3.

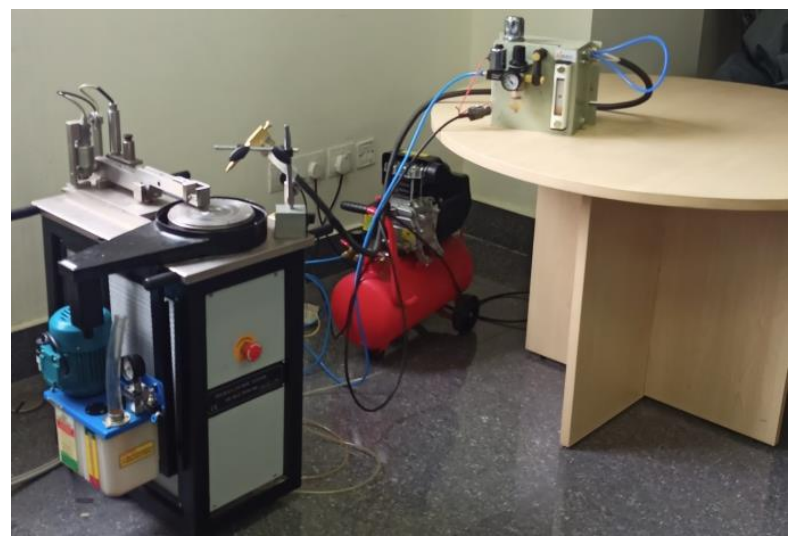

Fig. 2. Setup for using water as MQL on tribometer 


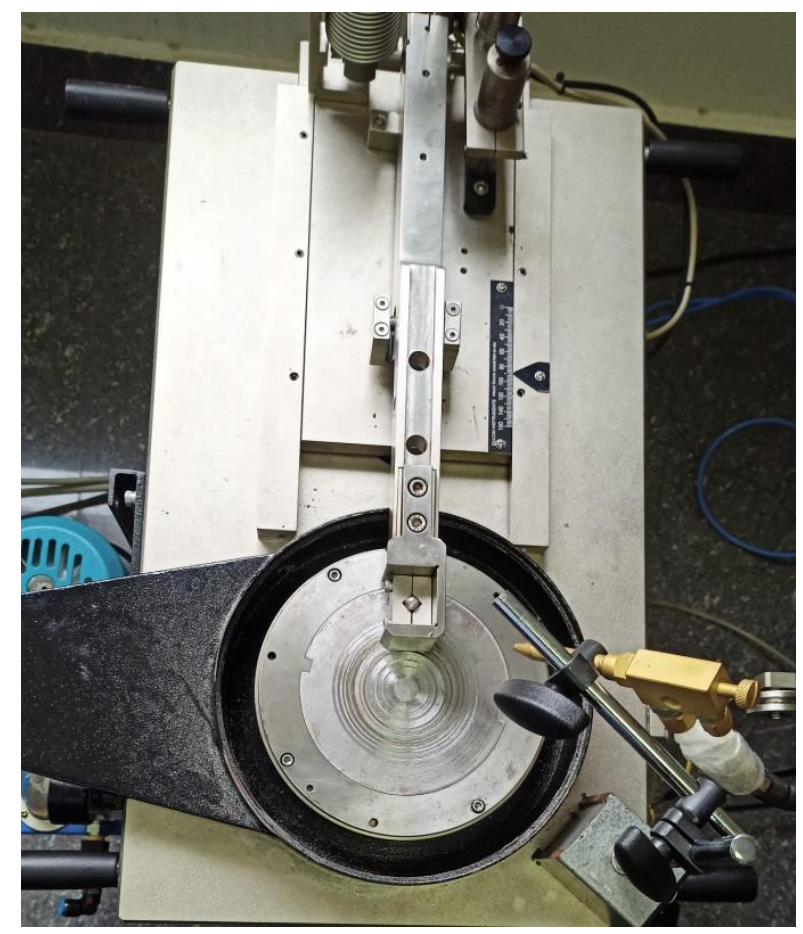

Fig. 3. Disk and pin holder with additional setup for MQL

For measurement of ambient temperature and relative humidity an additional sensor is used which have accuracy of $\pm 5 \%$ as shown in Fig. 4 .

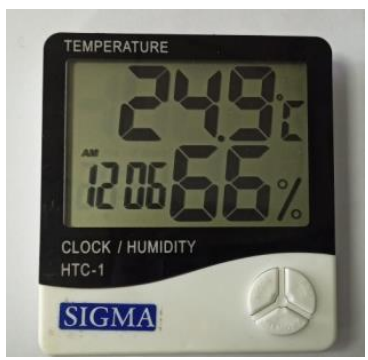

Fig. 4. Temperature and relative humidity during testing conditions

\subsection{Selection of materials and sample preparation}

The rail track and wheel material was provided by the Research Design and Standard organization Lucknow. The pin which is used in the test is made from rail track material and the disk is made from wheel. The materials' specifications are listed in table- 1 and table- 2 .

Table 1. Chemical composition and grade of materials [21]

\begin{tabular}{|c|c|c|}
\hline Specification & Wheel Material & $\begin{array}{c}\text { Rail Track } \\
\text { material }\end{array}$ \\
\hline Grade & IRS: R19/93 & 880 \\
\hline $\mathrm{C} \%$ & 0.52 & $0.60-0.80$ \\
\hline $\mathrm{Mn} \%$ & $0.60-0.80$ & $0.80-1.35$ \\
\hline $\mathrm{P} \%$ & 0.03 & 0.03 \\
\hline $\mathrm{S} \%$ & 0.03 & 0.03 \\
\hline $\mathrm{Si} \%$ & $0.15-0.4$ & $0.10-0.50$ \\
\hline $\mathrm{Al} \%$ & - & 0.015 \\
\hline
\end{tabular}

Table 2. Mechanical properties of materials [21]

\begin{tabular}{|c|c|c|}
\hline Specification & $\begin{array}{c}\text { Wheel } \\
\text { (IRS :R19/93) }\end{array}$ & $\begin{array}{c}\text { Rail (grade } \\
\mathbf{8 8 0})\end{array}$ \\
\hline $\begin{array}{c}\text { Yield Strength } \\
\text { (MPa) }\end{array}$ & $\begin{array}{c}50 \% \text { of Ultimate } \\
\text { Tensile Strength }\end{array}$ & 460 \\
\hline $\begin{array}{c}\text { Ultimate } \\
\text { Tensile Strength }\end{array}$ & $820-940$ & 880 \\
\hline
\end{tabular}

The fabricated pin has $8 \mathrm{~mm}$ diameter and has a length of $30 \mathrm{~mm}$. The fabricated disk has maximum track diameter of $110 \mathrm{~mm}$.

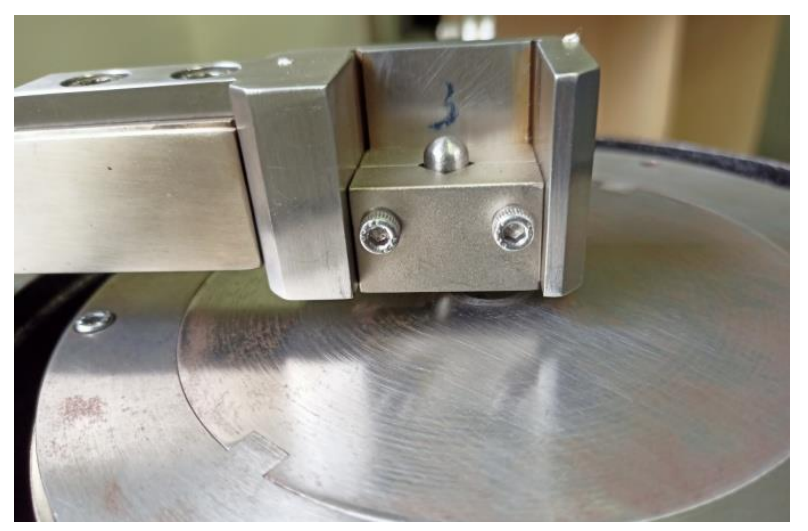

Fig. 5 The figure is showing the fabricated pin in the pin holder, disk and the track diameter which is visible below pin holder

\subsection{Test Procedure}

The experiment is performed in three conditions under two different loads. The plans of experiments are as shown in Table 3. The temperature is room temperature which is fixed throughout the experimentation. The relative humidity is fixed at $66 \%$.

Table 3. Parameters of experiment

\begin{tabular}{|c|c|c|c|}
\hline Parameters & Dry & $\begin{array}{c}\text { MQL } \\
\text { (water) }\end{array}$ & Wet \\
\hline $\begin{array}{c}\text { Temperature } \\
{ }^{\circ} \mathrm{C} \text { ) }\end{array}$ & 24.9 & 24.9 & 24.9 \\
\hline $\begin{array}{c}\text { Relative } \\
\text { Humidity (\%) }\end{array}$ & 66 & 66 & 66 \\
\hline Load (N) & 5,10 & 5,10 & 5,10 \\
\hline $\begin{array}{c}\text { Sliding } \\
\text { Distance (m) }\end{array}$ & 100 & 100 & 100 \\
\hline Time (s) & 100 & 100 & 100 \\
\hline $\begin{array}{c}\text { Sliding } \\
\text { velocity (m/s) }\end{array}$ & 1 & 1 & 1 \\
\hline
\end{tabular}

To keep the sliding velocity constant, the track diameter and RPM of the disk is adjusted accordingly. The mist of fine water droplets is used with compressed air and the rate of consumption of the water in MQL is rate of $200 \mathrm{ml} / \mathrm{hr}$.

\section{Results and discussion}


Whole experimentation is done following the details of experiment as shown by Table 3 . The results revealed the behaviour of friction force versus time and wear versus time. The room temperature was constant at $24.9^{\circ} \mathrm{C}$. The relative humidity was constant at $66 \%$. Both were unchanged throughout whole experimentation.

\subsection{Analysis of frictional force}

The behaviour of friction force with time is shown in the Fig 6. The results are recorded at constant load of $5 \mathrm{~N}$. From the results it is clearly observed that the friction force is higher in dry conditions with no contaminants as compared to other two conditions. The friction level in case of wet condition is least among the three conditions. As the water here is acting as a lubricant by providing a thin film between the pin and disk.

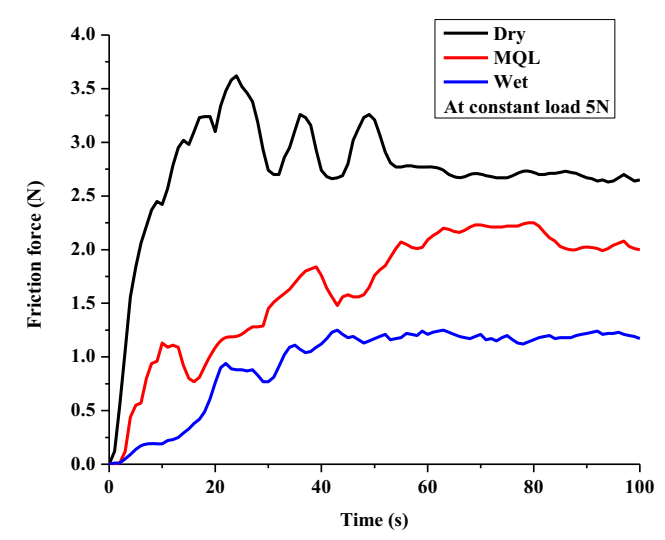

Fig. 6. Variation of friction force versus time at constant load of $5 \mathrm{~N}$

The other observation which is derived from the plot is that if the water is used as MQL at a rate of $200 \mathrm{ml} / \mathrm{hr}$, the friction level decreases when compared to the dry condition but when compared to wet, the friction levels are more than wet condition. The MQL condition is a representation of mist condition.

For all the three conditions the friction levels rise rapidly initially for around initial 20 seconds and then the curve flattens with some zigzag behaviour in each condition.

There is also another result of friction force versus time at a constant load of $10 \mathrm{~N}$ shown in Fig. 7. The second plot shows the same behaviour as stated above. The behaviour observed in Fig. 6 is confirmed that dry condition has higher friction level. Wet has lowest of all friction level. Use of water as MQL (representing mist) shows that the friction levels decrease significantly as compared to dry.

Another observation from the graphs at two loads $5 \mathrm{~N}$ and $10 \mathrm{~N}$ respectively shows that with increase in load, the friction force increases and this behaviour is for all three conditions.

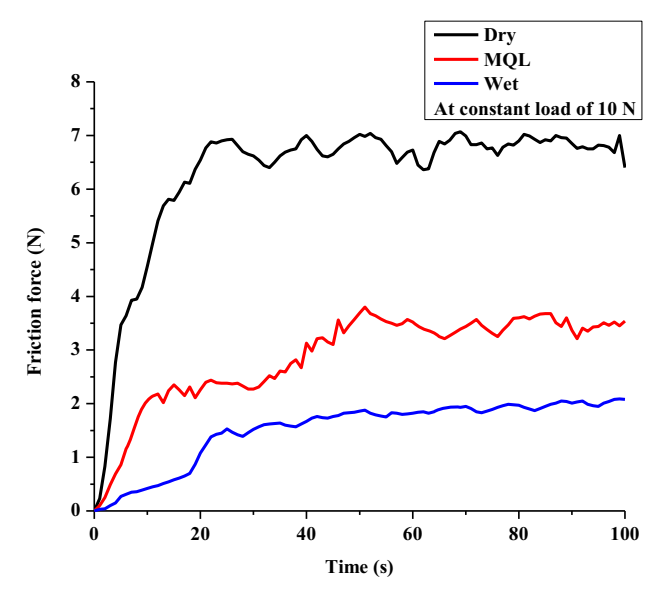

Fig. 7. Variation of friction force versus time at constant load of $10 \mathrm{~N}$

It can be concluded that the friction coefficient decreases as amount of water is increased in between the rail wheel contact. There is low friction force in wet condition and MQL (mist) condition. The friction force is associated with the adhesion force [22]. The adhesion would be less in mist condition when compared with dry condition and is least of all in wet condition.

\subsection{Analysis of wear depth}

The conditions in which rail and wheel functions have an important role to play in wear. The wear versus time plot at constant load of $5 \mathrm{~N}$ is as observed in the Fig. 8.

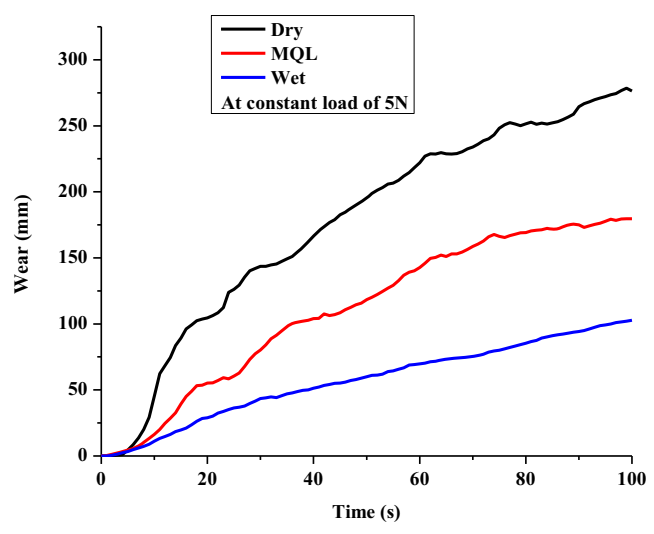

Fig. 8. Variation of wear versus time at constant load of $5 \mathrm{~N}$

As it can be clearly noted from the Fig. 8 that in dry condition, wear is maximum and it increases rapidly in the first 20 seconds and the curve is not smooth. The slope is the maximum for dry condition. The wear in case of MQL is less as compared to dry and hence slope is also less. The curve for wet condition has lowest wear and is also having minimum slope. The other observation is that, for the wet condition, the curve is smooth and more linear as compared other two conditions. 


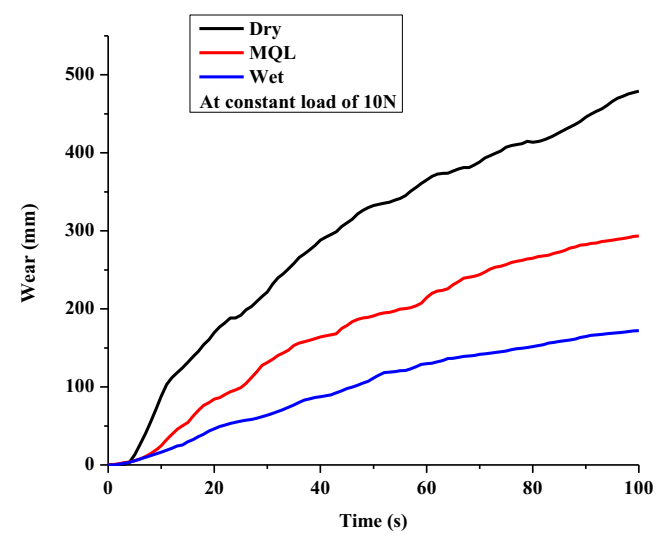

Fig. 9. Variation of wear versus time at constant load of $10 \mathrm{~N}$

The wear versus time at $10 \mathrm{~N}$ load is shown in Fig. 9. It is clearly visible that there is symmetry in conclusions drawn from the wear versus time graph at $5 \mathrm{~N}$ and at $10 \mathrm{~N}$. The Fig. 9 verifies the behaviour observed in Fig. 8. Wear for the dry condition is the maximum and for the MQL condition, it is less than dry condition and the wear is least for the wet condition.

The wear is increased in the $10 \mathrm{~N}$ case as compared to the $5 \mathrm{~N}$ case. Therefore, the wear is increased if the load is increased.

The rail and wheel has adhesion in the dry condition and therefore, adhesive wear takes place. But if water is there, it reduces the adhesion and hence the wear due to adhesion is reduced. The MQL condition, which is a representation of mist environment have effect on wear significantly. The amount of water is less in this as compared to wet condition and therefore, the wear is more but is less than in dry condition.

The wear slope decreases for all cases with increase in time, this is because of the fact, due to wear the contact area of pin and disk increases which in turn decreases acting pressure though the load is constant. This observation is in line with the study done by Ravikiran et al. [17]

\section{Conclusion}

The experiments performed on pin-on-disk tribometer when using pin of rail track material and disk of wheel material brings us following conclusions.

- The friction force as well as wear is higher in the dry condition in rail wheel contact than other two conditions.

- The MQL condition which represents mist condition has less friction force as well as wear when compared to dry condition but is more when compared to wet condition.

- Wet condition is having least friction force and wear among all conditions. The water acts as lubricant in the rail wheel contact thereby reducing friction between them. Low friction force indicates that the adhesive force is also low therefore the adhesion would be less in rail and wheel contact in these conditions as compared to dry condition.
- Therefore, the wear is reduced in wet conditions as the wear in dry condition between rail and wheel without any contaminant is primarily due to adhesion (adhesive wear).

- The friction force as well as wear depth increases in all the conditions with increase in load.

Acknowledgements: The author is thankful to RDSO Lucknow for arrangement of the materials for test specimen, Ajeet Yadav for his kind help during the initial stages of this work and special thanks to Vineet Dubey, research scholar for his help during the experimentation.

\section{References}

1. A. Khalladi and K. Elleuch, J. Tribol., 139, 1(2017)

2. U. Olofsson, R. Lewis, and M. Harmon, CRC Press, 281(2019)

3. Y. Zhu, U. Olofsson, and H. Chen, Tribol. Lett., 52, 327(2013)

4. S. R. Lewis, R. Lewis, U. Olofsson, D. T. Eadie, J. Cotter, and X. Lu, Proc. Inst. Mech. Eng. Part F J. Rail Rapid Transit, 227,115(2013)

5. U. Olofsson and K. Sundvall, Proc. Inst. Mech. Eng. Part F J. Rail Rapid Transit, 218, 235(2004)

6. E. A. Gallardo-Hernandez and R. Lewis, Wear, 265, 1309(2008)

7. Y. Zhu, Y. Lyu, and U. Olofsson, Wear, 324, 122 (2015)

8. A. Yadav, V. Dubey, R. K. Singh, and A. K. Sharma, Recent Advances in Smart Manufacturing and Materials, 244 (2021).

9. F. H. Stott, Tribol. Int., 35, 489(2002)

10. Y. Lyu, E. Bergseth, and U. Olofsson, Sci. Rep., 6, 1 (2016)

11. W. J. Wang, P. Shen, J. H. Song, J. Guo, Q. Y. Liu, and X. S. Jin, Wear, 271, 2699 (2011)

12. H. Chen, T. Ban, M. Ishida, and T. Nakahara, Proc. Inst. Mech. Eng. Part J J. Eng. Tribol., 220, 571 (2006)

13. H. Chen, T. Ban, M. Ishida, and T. Nakahara, Wear, 265,1504 (2008)

14. C. Hardwick, R. Lewis, and D. T. Eadie, Wear, 314, 198 (2014)

15. U. Olofsson, Proc. Inst. Mech. Eng. Part F J. Rail Rapid Transit, 221, 385 (2007)

16. L. Deters and M. Proksch, Wear, 258, 981 (2005) 
17. A. Ravikiran and S. Jahanmir, Wear, 250, 980 (2001)

18. A. J. Barthel, M. D. Gregory, and S. H. Kim, Tribol. Lett., 48, 305 (2012)

19. H. Soleimani, Urban Rail Transit, 3, 227 (2017)

20. J. Tunna, J. Sinclair, and J. Perez, Proceedings of the Institution of Mechanical Engineers, Part F: Journal of Rail and Rapid Transit, 222, 271 (2007)

21. "Steel authority of India Ltd." .

22. J. S. Mcfarlane and D. Tabor, Proc. R. Soc. London. Ser. A. Math. Phys. Sci., 202, 244 (1950) . 